\title{
nature
}

\section{Benefits of federation}

A new association of European neuroscientists highlights the opportunities to establish a transatlantic balance of disciplinary activity, and the failure of others to achieve it.

A t their worst, learned societies are dismal, tiny, unrepresentative bodies. In such circumstances, they fail to win the confidence of researchers in their respective discipline in the two activities by which they can in principle best distinguish themselves: their meetings and their publications. At their best, on the other hand, learned societies win allegiance and catalyse coherence through conferences and publications that are lively, authoritative and widely attended or read. That success, especially if enhanced by strong profits from society journals, leaves them well placed to support the professional development of members and also, through their ability to advocate on behalf of a large na tional proportion of a particular scientific discipline, achieve clout in science politics.

Many US societies have that stature. Regarded enviously in other countries, those such as the American Society for Neuroscience, American Geophysical Union and American Physical Society provide services that attract strong membership from other countries a feat that even the best of their equivalent bodies abroad find difficult, to say the least.

But who are the equivalents elsewhere? In Europe the answer is, as usual, less than straightforward. The lack of international clout of societies in individual countries and the pursuit of a European vision have led researchers to form societies at the European level, with decidedly mixed and - in comparison with the United States - typically lacklustre results. The success of neuroscientists in setting up a strong association (see page 614) is therefore good news. It also represents a model that other European ventures would do well to note.

One strength of the new body is that national societies have proved willing to modify their activities significantly in order to give the European Neuroscience Association space in which to fulfil itself. Just as importantly, the society is a federation of the national societies. Some European societies have adopted a mixed approach, simultaneously encouraging individual membership while also serving (and taking money from) the national bodies. That approach leads to the tempta- tion to provide services, such as members' magazines, that are intended to assert the identity and role of the society. Unfortunately, they end up costing a high proportion of the society's budget while achieving poor results due to inadequate resources. Thus the society and its members get the worst possible deal. Much better, if it can, for a European society to publish a revenue-earning journal, if necessary replacing several national journals in the process.

By such demarcation, strong, representative national societies can then be left to do what they do best - foster young scientists' development at national meetings, and represent their disciplines at the national level. Against the wishes of many smaller countries, Europe is stuck fast in a stable if undesirable situation lacking any coherent policy of transnational coordination in basic and strategic research - despite (or partly because of) the European Commission. National funding agencies jealously preserve their independence. In the circumstances, national societies' roles in promoting their members' interests continue to be important.

But whether the national societies like it or not, US societies prefer to operate with a partner at the European level, as do international agencies. Through its meetings and through its institutional contacts, a strong European society can foster international collaboration within and beyond Europe, and can generate support for researchers in poorer European countries.

In short, as long as there are some strong national societies in its discipline in Europe, a federated European society allows the community to get the best at both national and international levels. Those scientists, and those European societies, who strive rather towards an institution representing researchers as individual Europeans are living in a dream world in which there are European research councils, easy mobility of benefits and pensions, and harmonization of education and professional qualifications. Europe's science would do better in such circumstances, and strong European societies can only help hasten that day, but the vision is still a distant one.

\section{Keep dual funding}

The temptation to eliminate Britain's 'dual support system' for university research should be resisted.

In about four weeks' time, British scientists will discover just how deep is the commitment of the Labour government to a flourishing science base. That is when it is due to announce the outcome of its Comprehensive Spending Review, an exercise which, it is now clear, will set the boundaries of public spending over the next three years. There are grounds for optimism. A pre-election commitment to place science "at the heart of government" remains on ministers' lips. Increased spending on research would lie well with the oftenrepeated promise by Prime Minister Tony Blair that his top spending priority, after health and education, is investment for the future. Chancellor Gordon Brown has promised a slight relaxation in overall spending constraints. And officials from the Office of Science and Technology are reported to have presented a comprehensively documented case for spending an extra $\mathfrak{E} 500$ million a year on the science base.
But there is a cloud on the horizon which many thought had dissipated, but which reappeared last week. It took the form of reports that Treasury officials are once again canvassing reactions to the proposal for a substantial transfer of public research funds from the four regional university funding councils to the research councils. The apparent logic behind this proposal is clear: research councils are better placed to target research funding to those groups in universities able to use them most productively.

But to follow it would be a recipe for short-term management of university departments in efforts to secure funds at the expense of longer-term research planning. The 'dual support system' may not be ideal, and one should require, as the Dearing committee proposed last year, that research councils pay a fairer proportion of the costs of the research they sponsor. But to abolish the system will undermine, not strengthen, the UK's research base. 